Island Studies Journal, Vol. 2, No. 2, 2007, pp. 163-176

\title{
Contrasting Socio-Economic and Demographic Profiles of Two, Small Island, Economic Species: MIRAB versus PROFIT/SITE
}

\author{
Ashley Oberst \\ Associate Development Program, Countrywide Financial Corporation \\ West Hills, CA 91304, USA \\ Ashley_Oberst@Countrywide.com
}

and

Jerome L. McElroy

Department of Business Administration and Economics

Saint Mary’s College, Notre Dame, IN 46556, USA

jmcelroy@saintmarys.edu

\begin{abstract}
The MIRAB model developed by Bertram and Watters, based on remittances and aid, has dominated the small island economy literature for two decades. Recently, two challenges have surfaced: the PROFIT formulation emphasizing domestic policy flexibility - a socalled 'resourcefulness of jurisdiction' - and a dynamic private sector (Baldacchino, 2006); and the SITE model, stressing the role of tourism (McElroy, 2006). To date, there has been no comparative assessment of these different island models. This article addresses this gap. Its point of departure is to consider SITE islands as a subspecies of the PROFIT cluster. It constructs comprehensive profiles across 27 socio-economic and demographic variables for two island sub-groups with populations of less than three million: 23 MIRAB and 35 PROFIT-SITE. Results indicate PROFIT-SITE islands are much more affluent, socially advanced and demographically mature than their MIRAB counterparts.
\end{abstract}

Keywords: small island economy, MIRAB, PROFIT, SITE.

Copyright @2007 Institute of Island Studies, University of Prince Edward Island, Canada.

\section{Introduction}

Recently debate has been joined over the appropriate model(s) that best captures the structure, behaviour and development strategy of small island economies. For two decades the dominant paradigm has been the MIRAB formulation of Bertram and Watters (1985) which postulates that islands export labour and diplomatic services (UN votes, etc.) in exchange for a standard of living based mainly on corresponding remittances and aid from patron countries. However, very recently two simultaneous challenges have surfaced as alternatives to the MIRAB orthodoxy. In the first case, Baldacchino and Milne (2000) have argued that small societies, particularly sub-national island jurisdictions (SNIJs), have manipulated their amorphous and elastic jurisdictional status to carve out tax, finance, resource ownership, trade and other concessions from their respective metropolitan patrons. This so-called PROFIT model (Baldacchino, 2006a) emphasizes domestic policy 
flexibility and ingenuity, and a dynamic private sector. In the second case, McElroy (2006) has stressed the role of labour-intensive tourism development and related construction as a major engine of insular modernization. These small island tourist economies (SITEs) are primarily characterized by postwar diversification and aggressive tourism promotion.

To date, there has been no rigorous comparative assessment of these various models or species of island economy. In what ways do they fit with, and correspond to, island reality? With the exception of Bertram and Poirine (2007), much of the empirical work has been descriptive, fragmentary, narrow in scope, and/or based on case studies. This article attempts to address this lacuna in three ways. First, it compiles a rich data set on socioeconomic and demographic structure and behaviour of a large cross-section of small islands with a population of less than three million. Second, it constructs all-inclusive contrasting profiles using mean difference analysis between two subgroups: MIRAB islands prominently identified in the literature and an all-inclusive cluster of PROFIT-SITE islands that share the common feature of restructuring away from colonial agriculture (towards tourism, offshore finance or high-value manufacturing exports). A common legacy of deliberate and substantial postwar diversification and/or export substitution sets them apart from their MIRAB counterparts. Thus, the point of departure of this study is to consider SITEs as one of many sub-species of the PROFIT cluster. Third, the article briefly assesses the performance of MIRAB versus PROFIT-SITE: "two ideal-type strategies of economic development for small island territories” (Baldacchino, 2006a: 45).

\section{Literature}

The earliest serious attempt (Robinson, 1960) to assess the distinguishing contours of small economies (defined as ten-plus million inhabitants) did not focus specifically on islands. Nevertheless, these authors sounded many of the constraints that would later be refined and developed by island scholars: these include the disadvantages of a narrow production base, macroeconomic vulnerability to trade fluctuations, high administrative costs, and a tendency towards monopolistic domestic markets. On the other hand, Kuznets (1960: 31) identified a major advantage of small countries that is particularly relevant in today's era of aggressive globalization: "to use [their] stronger sense of community, the closer coherence of the population, the greater elasticity of social institutions, to overcome the disadvantages of small size." He saw in the small nation's capacity for "continuous and relatively painless adjustment" (1960: 32) the indispensable tool to achieve modern economic growth. Although he was well aware that some newly independent small states and islands were riven by ethnic, religious and linguistic cleavages, he stressed:

“ ... that in many small states there exists a strong feeling of community and solidarity, a product of a long-shared historical past, and that in these states social decisions, necessary for the adjustment to the potentials of economic growth, may be far easier to reach than elsewhere” (Kuznets, 1960: 29).

Island research began in earnest at the same time. The arc of the literature has traced roughly along three major threads emphasizing sequentially various aspects of (1) economic structure, (2) economic performance and (3) the role of domestic policy. The 
first wave of postwar pioneers focused on structural rigidities and natural barriers. For example, both Seers (1964) and Demas (1965) stressed the need for openness and intensive export engines to overcome the limitations of resource supply and capital goods incapacity; Knox (1967) emphasized the diseconomies of scale imposed by small domestic markets; and Selwyn (1978) touted remoteness as the major development constraint. A second wave of structuralists followed who again detailed specific handicaps transportation (Brookfield, 1990; Hein, 1990), export concentration (Jalan, 1982), the crowding out of domestic policy by a dominant multinational-driven foreign sector (Dommen \& Hein, 1985) - culminating in Briguglio's vulnerability thesis (1995) based on export market concentration, import dependence and a propensity for natural disaster.

The first island economy model based on the MIRAB structure was developed by Bertram and Watters (1985). They posited two stocks of labour, emigrant and public sector, and twin corresponding financial flows - remittances and aid - that sustained the standard of living in the face of a small and sluggish private sector. Over the next two decades, many small countries were identified as insular outposts relying on rural subsistence, primary exports, off-island labour and geo-strategic assets desired by their respective metropolitan patrons (Bertram, 2006). This model - MIgrant/Remittances and Aid/Bureaucracy dominated the literature until the recent surfacing of a second thread emphasizing performance. In a series of papers (1998, 2000, 2002), Armstrong and Read carefully established how small, mainly island, economies outperform their larger counterparts, a finding also noted by Poirine (1998) and identified in McElroy and Mahoney's (2000) study of Caribbean and Pacific islands. These authors pinpointed this behavioural advantage in diversification primarily towards tourism and offshore banking, and secondarily toward light export manufacturing. In follow-up work, McElroy and Pearce (2006) conclusively demonstrated that small SNIJs are not only more affluent than their sovereign neighbours, but also more socially advanced and demographically mature.

In their examination of North Atlantic islands, Baldacchino and Milne (2000) identified the core element in the second model and in so doing explicated the third thread: the central role of domestic policy in explaining the advantages enjoyed by these SNIJs. Given their often elastic legal status as offshore territories - not integrated states or provinces or independent countries - the authors identified their policy room to maneuver as the strategic use of jurisdictional autonomy to manipulate metropolitan ties for local benefit. Later, Baldacchino (2006a) formalized this idea in the so-called PROFIT model whereby SNIJs, through creative diplomacy and flexible policy, wrest local control from metropolitan powers over People (immigration), Resources, Overseas management (Diplomacy), FInance and Transport. The three aspects that distinguish PROFIT from MIRAB models are: the dynamism of the private sector, the active role of domestic policy, and the strategic orientation towards diversification. PROFIT examples would include tax and insurance havens, offshore banking centres, and duty-free manufacturing exporters.

At about the same time, McElroy (2006) introduced the third model, the so-called SITE formulation, to explain how many Small (warm water) Island Tourist Economies, particularly in the Caribbean, had overcome their size handicaps by restructuring their colonial monocrop economies toward the most sustained growth engine in the postwar 
global economy. This term was coined by Shareef (2004) to describe specialized tourist islands heavily reliant on foreign direct investment in infrastructure and facilities and characterized by GDP growth volatility (itself a function of natural disasters and excessive export concentration), loss of preferential export markets, and in some cases drastic declines in per capita aid following the post-1990 collapse of the Soviet Union. McElroy's work confirms that: "Smallness per se can be good for growth as long as it is combined with tourism specialization” (Brau et al., 2003: 9). In addition, he demonstrated that there were considerable socioeconomic and demographic distances between the most affluent SITEs and several MIRAB islands, and between SNIJs and sovereign islands; and he connected these differences to the tourism-conducive advantages of affiliation (such as same language, currency and customs for patron visitors, and no passports) as well as special tax and duty-free trade concessions from the metropole.

In his summary of this new generation of research, Bertram (2006: 1) pointed to "the emergence of a new, three-way taxonomy of small island socio-economic formations, comprising MIRAB, PROFIT and SITE ideal types.” He also argued (2006: 6): “A rich research agenda clearly remains to be explored." In an extensive follow-up study, Bertram and Poirine (2007) empirically established the rough economic contours of nine separate insular subspecies underneath the three ideal types, based on different strategies employed for funding imports. These included: high-value tourism, tourism plus offshore finance, tourism plus exports, and primary exports plus aid and/or remittances. To help inform and define such further speciation, the present study provides a first comprehensive empirical review of two of the three ideal island types, MIRAB and a PROFIT-SITE combination. This benchmark is secured by constructing contrasting profiles to determine the real-world validity of these alternative models and assess their relative levels of development.

Two operative assumptions guide this undertaking. First, SITE islands are considered a subspecies of the PROFIT genre. This conclusion is implicit in the recent literature. For example, SITEs are often linked with export processing zones and offshore banking centres. According to Baldacchino (2006b:2), many SNIJs:

“... have managed to deploy their jurisdictional power as a resource, extracting asymmetrical concessions from the metropole and using the resulting political space to carve out a more sustainable economic development trajectory-based on niche manufacturing, tourism, shrewd use of environmental and heritage resources, banking and finance.”

More explicitly, Baum (2000: 229) states: "Jurisdictional competence appears to be a major determinant of tourism development in cold water island destinations in the areas of transport and special tax exemptions such as duty-free shopping." This echoes the common theme in warm-water island research (Pattullo, 1996) of the prominent role government policy plays in such issues as promoting tourism, designing tax holidays to attract foreign hotel investment, and negotiating airline access. Because of these similarities, SITEs can be legitimately clustered underneath the PROFIT umbrella. 
Second, on the other hand, MIRAB economies represent a separate subset of islands distinct from their PROFIT-SITE neighbours. Although they may share certain traits to some degree, the dominantly MIRAB economy is identified be a special confluence of defining dimensions. In contrast to PROFIT-SITE destinations, the MIRAB economies generally exhibit relatively large public sectors, less effective use of jurisdictional power to create dynamic private sectors, lower levels of post-colonial restructuring and economic modernization, and a more systemic dependence on aid and remittances to maintain living standards. In addition, the traditional pursuits of small-scale agriculture and fishing tend to be much more prominent in many MIRAB islands, while their geographic remoteness as "outposts on the fringe of world capitalism" (Bertram, 2006: 2) inhibits the growth of other forms of private sector activity. These characteristics set them apart from their PROFITSITE counterparts and justify exploring these differences more systematically.

\section{Methodology}

This section covers three tasks: variable selection, island selection and various rationales used to classify islands into respective PROFIT-SITE and MIRAB categories. First, to create data-rich profiles of a large subset of small islands, it was necessary to use two standard sources: the CIA World Factbook (2007) for the socio-economic and demographic data, and the WTO Compendium of Tourism Statistics (2006) for the tourism indicators. Both permit detailed comparisons across a large sample of islands. However, as is often a problem in cross-sectional analysis, single-year measures (net migration, population growth, unemployment rate) that may be distorted by one-time events may poorly reflect stable and/or long-run patterns. In addition, the country selection between the two standard sources differs somewhat. As a result, some small SNIJs were omitted because they were excluded by The Factbook (Hawaii, Reunion) or by the Compendium (Faroe Islands, Wallis and Futuna). Moreover, although The Factbook provides a large quantity of information on many countries, the quality can be suspect because some of the data are extracted from unsourced and/or unreliable references particularly for small remote island nations, and in some cases variable values are missing. These weaknesses are enduring handicaps for island researchers engaged in large-scale cross-sectional analyses such as the present study, and suggest the need for caution in interpreting results.

To create comprehensive profiles, 27 variables were selected. Of these, roughly half were economic indicators. Five were employed to measure macro-economic performance and/or potential: per capita GDP (PPP), electricity consumption as a standard of living proxy, unemployment, and population and land area $\left(\mathrm{km}^{2}\right)$ as indicators of resource availability. Five were used to examine economic structure: the GDP shares of agriculture and services, and the labour force shares of agriculture, industry and services. Because of its significance in small islands, four indicators were chosen to measure the influence of tourism. These included two indirect measures of tourism infrastructure: number of airports with paved runways and the number of kilometres of paved roadways - and two more direct measures, the ratio of annual tourists to the resident population and tourist spending per resident: both calculated from WTO (2006). Tourists were defined as the number of stopover visitors plus the number of day-trippers divided by seven, the customary mean length of stay for overnight visitors. 
A dozen variables were employed to measure social and demographic differences. Three were used to gauge general social/health progress: adult literacy, life expectancy and infant mortality. Since demographic patterns often parallel development advances, nine variables were used to measure demographic differences: population growth, median age, the distribution of young (0-14), working age (15-64) and old (65+) cohorts, crude birth, death and net migration rates as well as the total fertility rate. Finally, because of the frequent appearance of its explanatory power in the literature, political status was included as a dummy variable with one (1) representing dependent SNIJs and zero (0) representing sovereign islands.

To operationalize the profiles, following Armstrong and Read (2000), small size was defined as a population threshold of less than three million, falling midway between the UN definition of one million and UNCTAD's threshold of five million. Fifty-eight islands with relatively complete data across the 27 variables met this criterion. In fact, most were relatively small with only three having populations above one million: Jamaica (2.8), Mauritius (1.3) and Trinidad-Tobago (1.1).

To classify island jurisdictions into MIRAB and PROFIT-SITE categories, in the absence of established quantitative criteria, primary appeal was made to the literature. To resolve cases where islands overlapped categories or where the literature was in conflict, justifications appealing to various MIRAB characteristics discussed above were provided. For example, although Baldacchino and Bertram (2007: 11) classify New Caledonia and St. Helena as MIRAB/PROFIT, these islands were here designated as dominantly MIRAB primarily because of the large inflows of per capita aid in 2004 of US $\$ 2,360$ and US $\$ 3,580$ respectively (CIA, 2007). Similarly, Nauru, depleted of its phosphate reserves, now subsists on per capita aid of US\$1,400 from Australia and is here considered MIRAB. Likewise, the same authors categorize American Samoa, Falkland Islands and Vanuatu as PROFIT, but they are here designated as MIRAB partly because agriculture and fishing account for the bulk of economic activity and partly because of their remoteness from the engines of world commerce.

As a result of these procedures, 23 islands were identified as MIRAB and 35 as PROFITSITEs (see Table 1). Five cases require some further clarification. First, even though Dominica has one of the fastest growing cruise sectors in the Caribbean (McElroy, 2006), it was classified as MIRAB because agriculture accounts for nearly a fifth of GDP. Second, Montserrat, formerly a long-stay vacation haven for North Americans, was downgraded to MIRAB status because volcanic eruptions in 1995 destroyed most tourism infrastructure leaving half the island uninhabitable (CIA, 2007). Presently the remaining population subsists on remittances and a multi-year UK aid package to rebuild the economy. Third, the Cook Islands was classified as PROFIT-SITE although it has traditionally been categorized as MIRAB (Bertram \& Watters, 1985). This revision was based on more recent research suggesting (Bertram \& Poirine, 2007: 336-337): “The Cook Islands [has] made a full transition out of MIRAB status" with roughly a third of the labour force presently engaged in tourism. Fourth, Iceland was classified as PROFIT-SITE largely because it represents the most tourist-penetrated among cold-water destinations and the 
one most likely to advance into high-density mass tourism status (Gössling, 2006). Finally, Trinidad and Tobago was classified as PROFIT-SITE, although tourism accounts for only $15 \%$ of GDP, largely because the smaller island of Tobago "... is one of the most touristintensive economies in the world” (WTTC, 2005:6).

To construct statistically distinct profiles, mean values across the 27 variables were calculated for each island grouping, and statistical differences were estimated using a twosample means test. Based on implications from recent research, it was hypothesized that the PROFIT-SITE economies would economically outperform their MIRAB counterparts and demonstrate a stronger orientation toward export services (tourism, offshore finance). As a consequence of their higher level of development, it was further assumed that the former would exhibit higher levels of social progress and greater demographic maturity.

\section{Results}

The basic data are compiled in the Appendix, while Table 2 displays the average values for the 27 variables classified by island grouping as well as the level of statistical significance (P-values) calculated by the two-sample means test. In almost every case, the mean differences conform to the hypothesized directions. Both island types are uniformly small in area averaging less than $5,000 \mathrm{~km}^{2}$, although PROFIT-SITEs exhibit higher human resource endowments and population density levels. The sharpest and one of the most statistically significant contrasts is between levels of affluence. Per capita GDP in PROFIT-SITEs (US\$19,532) averages over four times higher than MIRAB income (US\$4,570). Likewise the average level of electricity consumption for the former $(1,595$ million kwh) is over ten times the mean for the latter (131 million kwh). In addition, the average unemployment rate for PROFIT-SITE islands (11.1\%) is roughly half the level for MIRABs (21.6\%) although the difference is statistically significant only at the six percent level, most likely because of small sample sizes and wide variance.

These different levels of performance derive in part from different types of economic structure. MIRAB islands, in contrast to their PROFIT-SITE neighbours, tend on average to be more oriented toward traditional agriculture and subsistence and less restructured toward income-elastic exports like tourism, offshore banking and light manufacturing exports. According to Table 2, approximately a fifth (24.6\%) of GDP in MIRAB economies is accounted for by agriculture versus only $4.8 \%$ in PROFIT-SITEs. On the other hand, roughly three-quarters of GDP in the latter is service activity in contrast to only $58 \%$ in MIRAB islands. Similar differences show up in labour force deployment. For example, agriculture accounts for an average of $40 \%$ of jobs in MIRAB economies versus only $16 \%$ in PROFIT-SITEs, while services account for $45 \%$ and $63 \%$ respectively. Since the two island groups share roughly the same relative levels of industrial activity (20\%) and employment (25\%), one might argue that these structural differences may be more statistical than real due to the mirror-image or reflexive nature of the agricultural versus service ratio. However, analysis of both the composition of islands in each group as well as the tourism indicators below suggests that much of the differences are real. 
As a case in point, these structural differences are not surprising since the PROFIT-SITE group contains many of the most popular tourist destinations in the Caribbean (Aruba, Bahamas, Turks and Caicos, U.S. Virgins) as well as successful resort islands in the Indian (Maldives, Mauritius, Seychelles) and Pacific (Guam, Marianas, French Polynesia) Oceans. This group also boasts some of the major offshore tax havens and finance centres in the global economy: Bermuda, British Virgin Islands, Cayman Islands, Guernsey, and Isle of Man. On the other hand, the MIRAB group includes many remote, partially modernized agricultural/subsistence economies: the two Samoas, Cape Verde, Comoros, Kiribati, Micronesia, Solomon Islands and Vanuatu.

Although there is no direct evidence that political status and, by assumption, the judicious use of jurisdictional resources provide an empirical basis for superior economic performance, there is some indirect evidence that domestic policy, specifically tourism promotion, plays a role. For example, although only marginally larger in area, PROFITSITE islands averaged almost twice as many airports with paved runways as their MIRAB neighbours (5.1 versus 2.8). In addition, the former averaged over four times the latter in kilometres of paved roads (2,026 versus 447). Partly as a result of this greater provision of tourism infrastructure, PROFIT-SITE economies enjoyed significantly higher levels of international tourists and visitor spending than their MIRAB counterparts. To illustrate, their gross ratio of tourists to local population was six times higher - 3.83 to 0.58 - and their visitor spending per resident nearly nine times higher: US\$3,715 to US\$421. Such outcomes suggest, on average, that these PROFIT-SITE islands have deliberately and successfully restructured toward tourism and other export services to overcome the constraints of resource scarcity and remoteness.

In concert with these economic differences, the two island profiles also diverge across measures of social advancement and health. According to Table 2, for example, the PROFIT-SITE group averaged significantly higher life expectancy (75 years) than the MIRAB group (70 years). The former also demonstrated markedly higher adult literacy (95\%) than the latter (87\%), and enjoyed an infant mortality rate (12.9) less than half the level of the latter (28.2). These differences in social progress and health achievement are consistent with the different levels of per capita income noted earlier.

Similarly, the two demographic profiles contrast sharply across most indicators. PROFITSITE islands exhibit a significantly older age structure than their MIRAB neighbours. In the former, the median age is nearly nine years older: 32 to 23 years; on average, they also possess a much lower share of young (0-14 yrs.) cohorts: 25 versus 35 percent. PROFITSITEs also demonstrate a significantly higher share of working-age (15-64 yrs.) cohorts, that is: 60 - 68 percent. These discrepancies in labour force participation rates largely reflect, on the one hand, the more dynamic PROFIT-SITE economies and their associated more buoyant employment opportunities, and on the other hand the more stagnant activity in the MIRAB islands. They also reflect the demographic effects of a steady influx of workers in the former to service the labour-intensive demands of rapid tourism growth and offshore activity; and in the latter a sustained emigration related to the drive for remittances. Lastly, a significantly higher ratio of older (65+ yrs.) cohorts - 8\% versus 5\% - may partly reflect the relative appeal of PROFIT-SITE islands as retirement destinations. 
Previous research identified the importance of net migration behaviour as a discriminating variable between MIRAB and non-MIRAB islands (McElroy \& Morris, 2002). In the present study, however, the differences are not statistically significant, even though PROFIT-SITE economies averaged positive net immigration while MIRAB islands averaged net emigration of roughly two persons per 1,000 population. Some specific examples hint at the differences (see Appendix). Net emigration from three MIRAB islands - Samoa, Cape Verde, and Micronesia - was respectively 10, 12 and 21 persons per 1,000 population, signifying a population loss of $1-2 \%$ per year. On the other hand, net immigration into three of the fastest growing tourism and offshore centres in the Caribbean - British Virgin Islands, Turks and Caicos, Caymans - ranged between 10 and 17 persons per 1,000 population, likely swelling the local labour pool and fueling domestic demand.

Finally, the two groups differ in demographic behaviour. PROFIT-SITE islands demonstrated greater progress through the demographic transition from higher to lower birth and death rates. To illustrate, they averaged a notably lower crude birth rate than their MIRAB counterparts, 16 versus 25 births per 1,000 population. Similarly, their mean total fertility rate was roughly two children per woman of child-bearing age, in contrast to the MIRAB average of 3.3 children. As a result, with similar crude death rates, the mean rate of natural increase (birth minus death rates) for PROFIT-SITEs was 9.4 births: half the rate (18.8) for MIRAB islands. In addition, the most recent mean annual population growth for the former was over $50 \%$ slower than for the latter: 0.9 to 1.4 percent. This PROFIT-SITE tendency toward reduced fertility, natural increase, and population growth - partly a reflection of their relative affluence, older age structure and better health levels - suggests their greater degree of demographic maturity vis-à-vis their MIRAB counterparts.

\section{Conclusion}

In this provisional study of islands with populations of less than 3 million, a sample of 58 islands was broken down into two basic models or species, based on their relative degree of diversification and classification in the literature. The two types included: 23 MIRAB economies supported by remittances from emigrant labour and metropolitan aid from the export of diplomatic services/leverage; and 35 PROFIT-SITE economies identified by their postwar restructuring away from colonial agriculture, their dynamic private sector, and their strong domestic policy orientation toward tourism, offshore banking and other exports. Comprehensive profiles were constructed from mean values across 27 economic, social and demographic variables to determine differences in economic performance and relative levels of modernization.

Results indicated that the two island models indeed enjoy real-world validity since 18 of the 27 indicators were statistically significant. In contrast to their MIRAB neighbours, PROFIT-SITE islands were found to have significantly higher per capita incomes and service employment and sharply lower unemployment and agricultural activity. They were also endowed with considerably more tourism infrastructure (paved roads, airports) and, as expected, markedly higher levels of tourist arrivals and per capita resident visitor spending. The major evidence offered to support this superior performance was an extensive pattern 


\section{A. Oberst \& J. L. McElroy}

of restructuring frequently mentioned in the literature (Armstrong et al., 1998; Baldacchino \& Milne, 2000) away from low-value income-inelastic staples toward high-value incomeelastic service and manufacturing exports.

In conjunction with their greater level of economic development, PROFIT-SITE islands also exhibited an enhanced degree of social and demographic progress vis-à-vis their MIRAB counterparts. In contrast to the latter, the former were characterized by uniformly higher levels of life expectancy and adult literacy and lower levels of infant mortality and fertility. In addition, they demonstrated an older population structure with a significantly higher share of working-age cohorts and assumed labour force participation, and a significantly lower share of young cohorts indicating both reduced population growth and future momentum. All such outcomes suggest hallmarks of greater demographic maturity. Finally, the study also determined that neither size - a proxy for resource availability - nor political status played any role in distinguishing the two island profiles.

In conclusion, from a development perspective, these results provide evidence of the ability of PROFIT-SITE islands to take advantage of the ladder of profitable economic options (Bertram \& Poirine, 2007: 36) offered by expanding globalization, opportunities often neither feasible nor cost-effective for their constrained and remote MIRAB counterparts. They also pave the way for further exploration at least in two directions. First, further cross-country profiles could be established that more clearly define and compare various subspecies of the two ideal-type clusters examined here similar to the suggested configuration sketched out in Bertram and Poirine (2007): high-value tourism versus tourism/offshore finance, primary-production versus mineral-extraction MIRAB, and so on. Second, using a longitudinal perspective, case studies could be undertaken to identify what external and internal factors condition the movement of insular economies out of one species and into another. The overriding principle guiding this process of economic speciation would remain the domestic restructuring underlined in this study, i.e. the so-called "capacity for flexible adjustment" (Baldacchino \& Bertram, 2007), in the face of an ever changing and unpredictable global environment.

\section{References}

Armstrong, H.W. \& Read, R. (2002) 'The Phantom of Liberty? Economic Growth and the Vulnerability of Small States', Journal of International Development, Vol. 14, No. 2, pp. 435-458.

Armstrong, H.W. \& Read, R. (2000) 'Comparing the Economic Performance of Dependent Territories and Sovereign Micro-States’, Economic Development and Cultural Change, Vol. 48, pp. 285-306.

Armstrong, H.W., de Kervenoael, R.J., Li, X. \& Read, R. (1998) 'A Comparison of the Economic Performance of Different Micro-States, and Between Micro-States and Larger Countries', World Development, Vol. 26, No. 4, pp. 639-656. 
Baldacchino, G. (2006a) 'Managing the Hinterland Beyond: Two Ideal-type Strategies of Economic Development for Small Island Territories’, Asia Pacific Viewpoint, Vol. 47, No. 1, pp. 45-60.

Baldacchino, G. (2006b) Offshoring Strategies: Lessons from Sub-National Island Jurisdictions. Paper presented to Islands of the World Conference IX, Maui, Hawaii (July).

Baldacchino, G. \& Bertram, G. (2007) 'The Beak of the Finch: Insights into the Economic Development of Small, often Island, Economies', Small States: Economic Review and Basic Statistics, Vol. 12 (forthcoming).

Baldacchino, G. \& Milne D. (eds.) (2000) Lessons from the Political Economy of Small Islands: The Resourcefulness of Jurisdiction, Basingstoke, Macmillan.

Baum, T. (2006) 'Tourism and Cold Water Islands in the Atlantic' in G. Baldacchino \& D. Milne (eds.) Lessons from the Political Economy of Small Islands, Basingstoke, Macmillan, pp. 214-229.

Bertram, G. (2006) 'Introduction: The MIRAB Model in the Twenty-First Century', Asia Pacific Viewpoint, Vol. 47, No. 1, pp. 45-60.

Bertram, G. \& Poirine, B. (2007) 'Island Political Economy' in G. Baldacchino (ed.) A World of Islands: An Island Studies Reader, Canada and Malta, Institute of Island Studies and Agenda Academic, pp. 332-378.

Bertram, G. \& Watters, R.F. (1985) 'The MIRAB Economy in South Pacific Microstates', Pacific Viewpoint, Vol. 26, No. 3, pp. 497-519.

Brau, R., Lanza, A. \& Pigliaru, F. (2003) 'How Fast are the Tourism Countries Growing? The Cross-Country Evidence’, FEEM Working Paper, No. 85/2003 (September), www.feem.it/NR/rdonlyres/59ADDAAD-7DD9-4098-82235DA32DA1F5D9/832/8503.pdf.

Briguglio, L. (1995) 'Small Island Developing States and their Economic Vulnerabilities', World Development, Vol. 23, No. 10, pp. 1615-1632.

Brookfield, H.C. (1990) 'An Approach to Islands' in W. Beller, P. d'Ayala \& P. Hein (eds.) Sustainable Development and Environmental Management of Small Islands, UNESCO-Parthenon, Paris, pp. 23-33.

Central Intelligence Agency (2007) The CIA World Factbook, Washington DC, Central Intelligence Agency, https://www.cia.gov/library/publications/the-worldfactbook/Index/html.

Demas, W.G. (1965) The Economics of Development in Small Countries, McGill University, Montreal. 
Dommen, E.C. \& Hein, P.L. (eds.) (1985) States, Microstates and Islands, London, Croom Helm.

Gössling, S. (2006) 'Iceland' in G. Baldacchino (ed.) Extreme Tourism: Lessons from the World's Cold Water Islands, Oxford, Elsevier, pp. 115-128.

Hein, P. (1990) 'Economic Problems and Prospects of Small Islands' in W. Beller, P. d'Ayala \& P.L. Hein, (eds.) Sustainable Development and Environmental Management of Small Islands, UNESCO-Parthenon, Paris, pp. 35-42.

Jalan, B.M. (1982) Problems and Policies in Small Economies, New York, St. Martin’s Press.

Knox, A.D. (1967) 'Some Economic Problems of Small Countries' in B. Benedict (ed.) Problems of Smaller Territories, London, Athlone Press, pp. 35-44.

Kuznets, S. (1960) 'Economic Growth of Small Nations' in E.A.G. Robinson (ed.) Economic Consequences of the Size of Nations, London, Macmillan, pp. 14-32.

McElroy, J.L. (2006) 'Small Island Tourist Economies across the Life Cycle', Asia Pacific Viewpoint, Vol. 47, No. 1, pp. 61-77.

McElroy, J.L. \& Pearce, K. (2006) 'The Advantages of Political Affiliation: Dependent and Independent Small-Island Profiles', The Round Table: Commonwealth Journal of International Affairs, Vol. 95, No. 386, pp. 529-539.

McElroy, J.L. \& Morris, L. (2002) 'African Island Development Experiences: A Cluster of Models’, Bank of Valletta Review (Malta), No. 26, pp. 38-47.

McElroy, J.L. \& Mahoney, M. (2000) 'The Propensity for Political Dependence in Island Microstates’, Insula: International Journal of Island Affairs, Vol. 9, No. 1, pp. 32-35.

Pattullo, P. (1996) Last Resorts: The Cost of Tourism in the Caribbean, London, Cassell.

Poirine, B. (1998) 'Should We Love or Hate MIRAB?' The Contemporary Pacific, Vol. 10, No. 1, pp. 65-105.

Robinson, E.A.G. (ed.) (1960) Economic Consequences of the Size of Nations, London, Macmillan.

Seers, D. (1964) 'The Mechanisms of an Open Petroleum Economy', Social and Economic Studies, Vol. 13, No. 2, pp. 233-242.

Selwyn, P. (1978) 'Small, Poor and Remote: Islands at a Geographical Disadvantage', IDS Discussion Paper, No. 123, Sussex, Institute of Development Studies. 
Shareef, R. (2004) 'Country Risk Ratings of Small Island Tourist Economies', Fondazione Eni Enrico Mattei, Note di Lavoro, Index No. 25, www.feem.it/Feem/Pub/Publications/WPapers/default.htm.

World Tourism Organization (2006) Compendium of Tourism Statistics, Spain, WTO.

World Travel and Tourism Council (2005) Trinidad and Tobago: The Impact of Travel and Tourism on Jobs and the Economy, London, WTTC, www.wttc.travel/bin/pdf/original_pdf_file/trinidadandtobago2005.pdf.

\section{Table 1: Island Identification}

MIRAB

American Samoa

Cape Verde

Comoros

Falklands

Dominica

Kiribati

Marshall Islands

Federated States of Micronesia

Mayotte

Montserrat

Nauru

New Caledonia

Niue

St. Helena

St. Pierre \& Miquelon

Samoa

São Tomé \& Príncipe

Solomon Islands

Timor-Leste

Tokelau

Tonga

Tuvalu

Vanuatu
PROFIT-SITE

Anguilla

Antigua \& Barbuda

Martinique

Aruba

Bahamas

Bahrain

Barbados

Bermuda

British Virgins

Cayman Islands

Cook Islands

Cyprus

Fiji

French Polynesia

Mauritius

Netherlands Antilles

Northern Marianas

Palau

St. Kitts and Nevis

St. Lucia

St. Vincent \& Grenadines

Seychelles

Turks and Caicos

U. S. Virgin Islands

Trinidad/Tobago
Grenada

Guadeloupe

Guam

Guernsey

Iceland

Isle of Man

Jamaica

Jersey

Maldives

Malta 


\section{Table 2: MIRAB and PROFIT/SITE Profiles}

Variable

MIRAB PROFIT/SITE P-Values ${ }^{1}$

\begin{tabular}{|c|c|c|c|}
\hline Area $\left(\mathrm{Km}^{2}\right)$ & 4,367 & 4,977 & 0.856 \\
\hline Population & 192,327 & 343,273 & 0.158 \\
\hline GDP per capita (USUS\$) & 4,570 & 19,532 & $0.000^{*}$ \\
\hline Unemployment (\%) & 21.6 & 11.1 & 0.060 \\
\hline Agriculture/GDP (\%) & 24.6 & 4.8 & $0.002 *$ \\
\hline Services/GDP (\%) & 58.2 & 74.6 & $0.000^{*}$ \\
\hline \multicolumn{4}{|l|}{ Percent Labour Force } \\
\hline in Agriculture & 40.2 & 16.0 & $0.024^{*}$ \\
\hline in Industry & 27.1 & 24.0 & 0.602 \\
\hline in Services & 44.6 & 63.3 & $0.009 *$ \\
\hline Electricity (million Kwh) & 131 & 1,595 & $0.001^{*}$ \\
\hline Tourists/population ${ }^{2}$ & 0.058 & 3.830 & $0.000^{*}$ \\
\hline Tourist Spending/Pop. (US\$) & 421 & 3,715 & $0.000 *$ \\
\hline No. Paved Airports & 2.8 & 5.1 & 0.117 \\
\hline Paved Roads (Km) & 447 & 2,026 & $0.020^{*}$ \\
\hline Crude Birth Rate & 25.1 & 16.1 & $0.000^{*}$ \\
\hline Crude Death Rate & 6.3 & 6.7 & 0.396 \\
\hline Population Growth (\%) & 1.40 & 0.91 & 0.088 \\
\hline Net Migration & -1.80 & 0.41 & 0.287 \\
\hline Total Fertility Rate & 3.30 & 2.10 & $0.000^{*}$ \\
\hline \multicolumn{4}{|l|}{ Percent Population } \\
\hline 0-14 yrs. & 34.7 & 24.5 & $0.000^{*}$ \\
\hline $15-64$ yrs. & 60.2 & 67.6 & $0.000^{*}$ \\
\hline $65+$ yrs. & 5.2 & 8.1 & $0.004^{*}$ \\
\hline Median Age (yrs.) & 23.3 & 31.5 & $0.000^{*}$ \\
\hline Political Status $^{3}$ & 0.391 & 0.514 & 0.366 \\
\hline Life Expectancy & 70.3 & 74.8 & $0.004^{*}$ \\
\hline Adult Literacy (\%) & 87.3 & 94.9 & $0.050 *$ \\
\hline Infant Mortality & 28.2 & 12.9 & $0.003^{*}$ \\
\hline
\end{tabular}

Sources: Data from (CIA, 2007), except 2 tourism indicators from (WTO, 2006).

Notes: 1. Asterisk (*) denotes statistical significance at the 0.05 level or better.

2. Tourists calculated as all overnight visitors plus day-trippers divided by seven, the average length of stay of overnighters.

3. Measured as 1.0 for dependents and 0.0 for independents. 